\title{
Labyrinthe
}

$6 \mid 2000$

Numéro 6

\section{L'enseignement privé en Loire-Atlantique 1969 - 1999 : la fragilisation du dernier « pilier de l’Église 》)}

\section{Damien Surget}

\section{(2) OpenEdition Journals}

Édition électronique

URL : http://journals.openedition.org/labyrinthe/413

DOI : $10.4000 /$ labyrinthe. 413

ISSN : 1950-6031

Éditeur

Hermann

\section{Édition imprimée}

Date de publication : 1 juin 2000

Pagination : 128-130

Référence électronique

Damien Surget, «L'enseignement privé en Loire-Atlantique 1969 - 1999 : la fragilisation du dernier « pilier de l'Église » », Labyrinthe [En ligne], 6 | 2000, mis en ligne le 20 mars 2005, consulté le 20 avril 2019. URL : http://journals.openedition.org/labyrinthe/413 ; DOI : 10.4000/labyrinthe.413

Ce document a été généré automatiquement le 20 avril 2019.

Propriété intellectuelle 


\title{
L'enseignement privé en Loire-
} Atlantique 1969 - 1999 : la fragilisation du dernier « pilier de
l'Église »

\author{
Damien Surget
}

Synthèse d'un mémoire de maîtrise de géographie soutenu en octobre 1999 sous la direction de $\mathrm{M}^{\mathrm{me}}$

Valérie Jousseaume à l'Université de Nantes.

1 L'Ouest de la France a une tradition de vieille terre de catholicité et l'enseignement privé y jouit d'une implantation forte, notamment dans les espaces ruraux. La Loire-Atlantique ne fait pas exception. En 1998, l'enseignement catholique y scolarisait près de quatre élèves sur dix de la maternelle au baccalauréat ${ }^{1}$, proportion étonnamment élevée au regard du relâchement contemporain des pratiques religieuses ${ }^{2}$. Or, la fréquentation de l'enseignement privé est un comportement qui s'inscrit sur le terrain au travers de la concurrence entre l'école privée et l'école publique dans chaque commune. Dès lors, il devient intéressant pour le géographe d'étudier la configuration spatiale de ce phénomène social. C'est dans cette perspective que nous avions entrepris notre travail de recherche.

2 À travers l'analyse, sur une durée de près de trente ans, de 1969 à 1998, de la géographie de l'enseignement catholique en Loire-Atlantique, nous nous sommes alors attaché à mettre en relation les évolutions de son audience dans les espaces du département avec les changements qui ont affecté les sociétés villageoises dans leurs structures (modification du tissu social), dans leur rapport à l'espace et à la religion (évolution de l'ancrage paroissial des populations) et dans leurs comportements politiques.

3 À l'origine, l'urbanité agissait comme un élément déstabilisateur pour l'enseignement catholique. L'opposition entre pays d'école privée et pays d'école publique reproduisait alors la frontière entre les villes et les campagnes du département, dont les rapports étaient fondés sur une méfiance réciproque. À la fin des années 1960, la primauté de 
l'école catholique soulignait la limite externe du front d'urbanisation nantais. Les deux agglomérations du département, Nantes et Saint-Nazaire, constituaient deux foyers de laïcité perdus au milieu d'espaces ruraux unanimement voués à l'enseignement confessionnel. En 1969, près de deux enfants sur trois fréquentaient l'école publique à Nantes et plus de trois sur quatre à Saint-Nazaire, cité portuaire à forte tradition ouvrière. Dans le reste du département, l'audience de l'enseignement primaire public ne dépassait pas $25 \%$. En d'autres termes, l'enseignement public trouvait les huit dixièmes de sa clientèle dans les deux pôles urbains du département, quand l'enseignement privé n'y recrutait guère plus de $40 \%$ de ses effectifs.

4 Au sein des espaces ruraux de la Loire-Atlantique, les effets perturbateurs de l'urbanité étaient pourtant perceptibles. On observait un relatif détachement à l'égard de l'enseignement catholique à partir d'un échelon urbain qui correspondait au gros bourg chef-lieu de canton. La part relative de l'école catholique s'élevait en effet à $51 \%$ dans les petites villes du département, à $64 \%$ dans les principaux bourgs-centres et à près de $80 \%$ dans les autres communes rurales ${ }^{3}$. Ces pôles ruraux du département étaient caractérisés par un profil social original qui en faisait des points d'ancrage d'urbanité au sein de l'espace rural.

5 En 1998, ces petits centres ruraux ne se distinguent plus des communes rurales traditionnelles. L'audience de l'enseignement catholique n'y est ni plus élevée, ni plus faible : $48,5 \%$ dans les petites villes, $49 \%$ dans les gros bourgs-centres et $51,5 \%$ dans les autres communes rurales. De même, les contrastes entre les villes et les campagnes se sont atténués sous les effets conjoints de la périurbanisation et des évolutions sociales : les vieilles fractures n'ont pas complètement résisté à l'usure du temps et aux changements socio-spatiaux, tandis que bourgs-centres et petites villes paraissent avoir connu une banalisation socio-culturelle. De fait, la géographie départementale de l'enseignement catholique a connu de profondes mutations : les effets de l'urbanité se sont atténués et l'homogénéité des espaces ruraux a laissé place à un contraste entre les deux rives de la Loire. Au nord du fleuve, l'enseignement catholique a connu une érosion très sensible de son audience, au point que les effectifs de l'école publique y sont désormais très souvent supérieurs à ceux de l'école privée. À l'inverse, au sud de la Loire, cette situation demeure exceptionnelle et la part relative de l'enseignement catholique atteint encore $70 \%$ dans certains cantons.

Nous avons ainsi fait le constat spatialisé d'évolutions inégales et différenciées et mesuré ce qui bouge et ce qui dure. L'explication de ces permanences et de ces changements passe alors par l'analyse des différentes sphères de la réalité, par une confrontation du social et du spatial qui " constituent un binôme dont chaque terme s'enrichit dans le décryptage de l'autre, tellement ils sont intimement liés ${ }^{4} »$.

7 Les évolutions contemporaines ont mis à mal le "système paroisse ", en déstructurant le tissu social des communes rurales, microcosmes désormais soumis aux influences urbaines et à la mobilité. Les liens se desserrent alors entre les comportements religieux, culturels, politiques et scolaires et la paroisse constitue aujourd'hui presque une " coquille vide ». Si le recul général de l'enseignement catholique paraît devoir être expliqué par la dissolution progressive des « sociétés paroissiales ${ }^{5}$ » d'antan, la lecture de la situation actuelle de l'enseignement catholique nous révèle que la désagrégation des " sociétés paroissiales " n'est pas chronologiquement homogène au sein de l'espace départemental. Le maintien de l'enseignement catholique au sud de la Loire témoigne d'une inégale résistance sociale de part et d'autre du fleuve. Aux marges des Mauges 
choletaises et de la Vendée, par ailleurs bien connues pour leurs industries rurales d'origine endogène, les pesanteurs sociales du passé paraissent encore plus influentes que les forces du changement. Pour paraphraser Alain Chauvet ${ }^{6}$, les populations rurales se souviennent davantage qu'elles ne choisissent (maintien d'un fort vote de droite et d'une pratique religieuse non négligeable). Dans les campagnes du nord du département, l'enseignement catholique apparaît en revanche de plus en plus comme une structure « relique » d'un système socio-spatial « paroisse » à l'agonie.

$\mathrm{Au}$ regard des dynamiques spatiales et sociales à l'œuvre, l'enseignement catholique fait toutefois preuve d'une surprenante pérennité. Il a en effet survécu au passage d'une société rurale agricole, enracinée et pratiquante à une société rurale diversifiée, mobile et largement déchristianisée en développant ses structures (mise en place très précoce d'établissements d'enseignement secondaire) et en adaptant ses filières de recrutement (importance de l'enseignement technologique). Mais son maintien relatif est avant tout la marque d'une forme de " catholicisme culturel ${ }^{7}$ ». À bien des égards, l'effritement progressif de l'audience de l'enseignement catholique dans les campagnes de LoireAtlantique apparait comme l'un des derniers avatars de la paroisse traditionnelle. Les relations entre les populations rurales et l'espace se renouvellent. Le "système paroisse " en fait les frais et la géographie de l'enseignement catholique en Loire-Atlantique en témoigne.

\section{NOTES}

1. En France, l'enseignement privé scolarise environ $17 \%$ des élèves. Sa part relative s'accroît au fil de la scolarité : en 1998, il accueille 12,5\% des élèves du pré-élémentaire, $15 \%$ du primaire, et $21 \%$ du secondaire. En Loire-Atlantique, l'enseignement privé catholique scolarise de 35 à $41 \%$ des élèves selon les degrés et les cycles d'enseignement. 2. Des estimations récentes de l'évêché de Nantes font état d'un taux de pratique religieuse régulière oscillant entre 7 et $8 \%$ en Loire-Atlantique.

3. Tous les chiffres cités dans le texte ont été établis à partir des données obtenues auprès des services de l'Inspection académique de Loire-Atlantique.

4. A. Frémont, J. Chevalier, R. Hérin et J. Renard, Géographie sociale, Paris, Masson, 1984, $220 \mathrm{p}$.

5. J. Renard, Les Évolutions contemporaines de la vie rurale dans la région nantaise, Le Cercle d'Or, Les Sables d'Olonne, 1976, $432 \mathrm{p}$.

6. A. Chauvet, « Le bourg et le village dans le canton de Saint-Fulgent », Norois, 1981, $\mathrm{n}^{\circ}$ 112, Poitiers, p. 483-509.

7. Y. Lambert, «Catholicisme et politique dans l'Ouest rural », ibid., p. 529-544. 